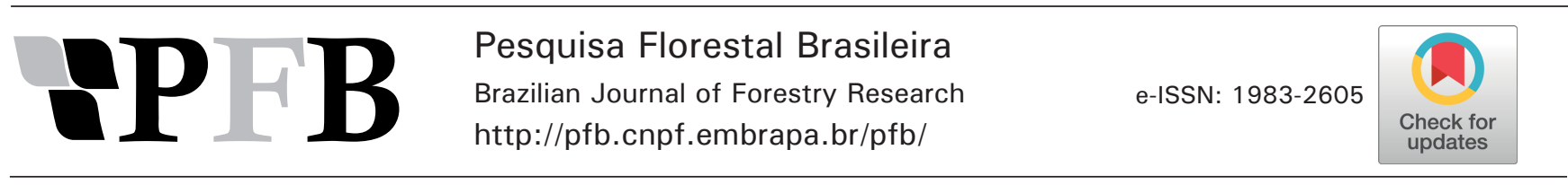

\title{
Quantificação do material combustível em fragmento de Mata Atlântica no nordeste brasileiro
}

\author{
Marcus Vinícius Noronha de Oliveira ${ }^{*}(\mathbb{D})$, Benjamin Leonardo Alves White ${ }^{(\mathbb{D}}$, Genésio Tâmara Ribeiro ${ }^{3(D)}$ \\ ${ }^{1}$ Secretaria do Estado da Educação, Colégio Estadual Eduardo Silveira, Rua Arthur Lourenço dos Reis, 146, CEP 49504-367, Itabaiana, SE, Brasil \\ ${ }^{2}$ Universidade Federal de Sergipe, Departamento de Biociência, Av. Vereador Olímpio Grande, s/n, CEP 49506-036, Itabaiana, SE, Brasil \\ ${ }^{3}$ Universidade Federal de Sergipe, Departamento de Engenharia Florestal, Av. Marechal Rondon, s/n, Jardim Rosa Elze, CEP 49100-000, São Cristóvão, SE, Brasil
}

*Autor correspondente:

mv_bioufs@hotmail.com

Termos para indexação:

Incêndios florestais

Perigo de fogo

Conservação

Index terms:

Wildfires

Fire hazard

Conservation

Histórico do artigo:

Recebido em 22/05/2017

Aprovado em 07/06/2018

Publicado em 13/11/2018

doi: 10.4336/2018.pfb.38e201701449

\begin{abstract}
Resumo - Em Sergipe, todos os anos, áreas protegidas da Mata Atlântica sofrem com incêndios florestais. Nesse cenário, fazem-se necessários estudos voltados para a compreensão do comportamento do fogo nestas áreas. O presente trabalho teve por objetivo quantificar o material combustível superficial em três diferentes formações vegetacionais presentes no Refúgio de Vida Silvestre Mata do Junco, Capela, SE. Em cada local foram demarcadas 20 parcelas de $2,25 \mathrm{~m}^{2}$, onde todo o material combustível foi coletado e classificado. As áreas de bambuzal $\left(7,60\right.$ t ha $\left.^{-1}\right)$ e mata fechada $\left(7,02\right.$ tha $\left.^{-1}\right)$ apresentam maior carga de material combustível, enquanto que as áreas de transição apresentaram valor inferior $\left(2,08 \mathrm{t} \mathrm{ha}^{-1}\right)$. $\mathrm{O}$ teor de umidade do material combustível também variou de acordo com a vegetação, apresentando valores médios acima da "umidade de extinção" nas áreas de mata fechada e de transição. A avaliação do perigo de ocorrência de incêndios revela que as áreas de bambuzal apresentam maior risco.
\end{abstract}

\section{Fuel load quantification in a brazilian northeast Atlantic Forest fragment}

\begin{abstract}
In Sergipe, every year, wildfires damage Atlantic Forest conservation units. Therefore, it is necessary to carry on studies that aims to understand fire behavior in such forests. This work intended to quantify the surface fuel load in three different vegetation types the Mata Junco Wildlife Refuge, in Capela, Sergipe State, Brazil. In each site 20 plots of $2.25 \mathrm{~m}^{2}$ were delimited, where all fuel load was collected and classified. Bamboo fields $\left(7.60 \mathrm{t} \mathrm{ha}^{-1}\right)$ and closed forests $\left(7.02 \mathrm{tha}^{-1}\right)$ presented the highest fuel load, while the transition areas presented lower value $\left(2.08 \mathrm{t} \mathrm{ha}^{-1}\right)$. The moisture content of the fuel load changed according to the vegetation type. In the closed forests and transition areas the moisture content was above the "moisture of extinction". The assessment of the wildfire hazard showed that the bamboo fields presented the highest fire hazard.
\end{abstract}

\section{Introdução}

Os incêndios florestais são uma das maiores ameaças à conservação da biodiversidade do planeta. Além de seu impacto direto sobre a fauna e a flora, contribuem diretamente com a degradação ambiental, deixando o solo mais suscetível a processos erosivos e liberando na atmosfera gases responsáveis pelo efeito estufa (Liu et al., 2010; Mataix-Solera et al., 2011).

No Brasil, a prática de queimadas durante os procedimentos de colheita da cana-de-açúcar e abertura de pastagens são muito comuns e remontam os tempos da colonização (Moreno et al., 2003). O problema reside em que muitas dessas atividades econômicas estão inseridas 
em áreas de relevante interesse ecológico. Incêndios em ecossistemas sensíveis ao fogo, a exemplo da Mata Atlântica e Floresta Tropical, além de representarem uma ameaça à biodiversidade e ao bem-estar humano, ameaçam o equilíbrio do clima na terra (Moretti \& Legg, 2009; Liu et al., 2010).

Em Sergipe, apesar de todos os esforços movidos pelos órgãos ambientais do estado, todos os anos áreas naturais importantes, como as do Parque Nacional Serra de Itabaiana, sofrem com problemas causados pelo mau uso do fogo (White et al., 2013a, 2014b). Diante disso, pesquisadores e órgãos ambientais têm se debruçado sobre alternativas sustentáveis que visem minimizar esse problema, além de compreender os diversos fatores que possuem influência direta sob a ocorrência dos incêndios florestais.

Variáveis meteorológicas como temperatura do ar, umidade relativa do ar, velocidade do vento e precipitação pluviométrica constituem os principais fatores determinantes para ocorrência e propagação de incêndios florestais. Tais variáveis influenciam diretamente o teor de umidade do material combustível florestal e, consequentemente, a quantidade de energia necessária para que a biomassa vegetal entre em processo de ignição (Torres et al., 2011; White et al., 2013b).

A quantidade de material combustível disponível também é um importante fator, atuando na propagação e intensidade do fogo (Soares \& Batista, 2007; Ribeiro, 2009). O material quantificado precisa ser classificado de acordo com classes de diâmetro pré-estabelecidas, chamadas de classes de timelag, com base no tempo de resposta que o material perde ou ganha umidade do ambiente (Rothermel, 1972; Fernandes \& Loureiro, 2013; White et al., 2013a, 2014a).

Além das condições meteorológicas e da carga do material combustível disponível, outros fatores influenciam no processo de ignição e na forma como o fogo irá se propagar, a exemplo da altitude, declividade e exposição do relevo, além de características físicas e químicas inerentes ao material combustível (Rothermel, 1972; Soares \& Batista, 2007; White et al., 2013c). O conhecimento de todos esses fatores é de fundamental importância para se estabelecer programas de prevenção e combate aos incêndios florestais, principalmente em áreas naturais protegidas. Esses dados podem ser processados em programas computacionais especializados (Andrews et al., 2003; Finney, 2004), sob os quais é possível simular parâmetros inerentes ao comportamento do fogo (White et al., 2013a, 2013c).

O presente trabalho teve por objetivo quantificar e classificar o material combustível superficial disponível, bem como seu teor de umidade, em diferentes formações vegetacionais em um fragmento de Mata Atlântica no estado de Sergipe, visando identificar e caracterizar áreas com maior risco à ocorrência de incêndios florestais.

\section{Material e métodos}

\section{Área de estudo}

O presente estudo foi realizado no Refúgio de Vida Silvestre Mata do Junco (RVSMJ), localizado no município de Capela, SE (Figura 1). Trata-se de uma área com 897 ha que apresenta relevante interesse ecológico, uma vez que abriga remanescentes de Mata Atlântica sob os quais é possível encontrar espécies raras, endêmicas e com alto risco de extinção, como é o caso do macacoguigó (Calicebus coimbrai) (Santos et al., 2007).

De acordo com Malta et al. (2011), esta área apresenta fragmentos típicos de Mata Atlântica de Tabuleiro, a qual se encontra bastante descaracterizada devido às transformações causadas por implantação de pastagens e plantações de cana-de-açúcar. No plano de manejo da unidade, o uso do solo foi categorizado em cinco distintas classes: florestas de tabuleiro; áreas degradadas de solos lateritizados; áreas agrícolas; pastagens abandonadas; e vegetação regenerante (Dantas et al., 2007).

\section{Determinação dos ambientes de coleta}

Foram analisadas as três formações vegetacionais predominantes no RVSMJ situadas próximas às plantações de cana-de-açúcar, uma vez que, em função dos procedimentos anuais de queima da palhada da cana, tais áreas estão mais suscetíveis a entrarem em processo de ignição.

As áreas denominadas de mata fechada são representadas pela fitofisionomia Floresta Estacional Semidecidual de Terras Baixas (IBGE, 2012), apresentando dossel fechado, bastante homogêneo e podendo chegar até $30 \mathrm{~m}$ de altura. No sub-bosque a luminosidade é baixa e a umidade é alta. Algumas espécies herbáceas são encontradas em conjunto com espécimes florestais jovens, principalmente em áreas de clareira. A presença de lianas e epífitas é marcante 


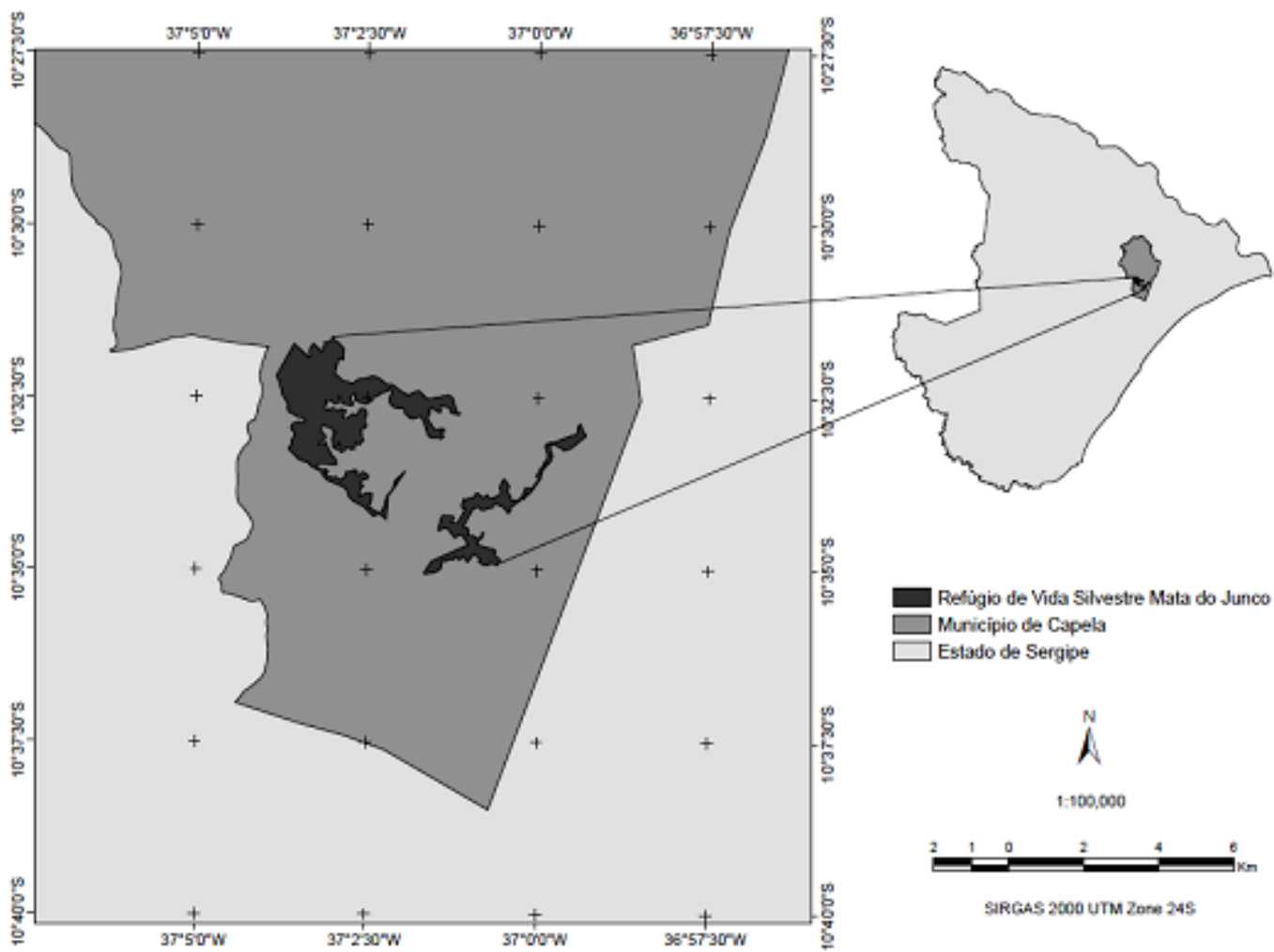

Figura 1. Representação do Refúgio de Vida Silvestre Mata do Junco, Capela, SE.

Figure 1. Representation of Mata do Junco Wildlife Refuge, Capela, Sergipe, Brazil.

(Dantas \& Ribeiro, 2010). As espécies mais comuns encontradas nesses ambientes são o murici (Byrsonima spp.), a pindaíba (Xylopia aromatica) e o ingazeiro (Lonchocarpus sericeus) (Souza, 2014).

As áreas de bambuzal, nesse trabalho, compreendem uma extensa faixa de Phylostachys aurea Rivière \& C. Rivière, a qual foi abandonada antes da criação da unidade e que faz fronteira com regiões de alto potencial biológico, a exemplo das matas fechadas. O bambu era utilizado para sombreamento das pastagens, mas ampliou sua área de ocupação após a criação da unidade de conservação e extinção da prática agrícola/pecuária (White et al., 2017). Nessas áreas, o dossel é mais aberto que nas matas, sendo assim, a temperatura do ar no sub-bosque é mais elevada. A serapilheira é composta principalmente por folhas secas que recobrem o solo por completo, sendo ausente a presença de espécies herbáceas e arbustivas (Dantas \& Ribeiro, 2010; White et al., 2017).

As áreas de transição são formadas por uma vegetação típica de áreas de regeneração em estágios primários e secundários em função de impactos antrópicos, especialmente pela extração de "taquaras" do gênero Merostachys. Nesses locais, as espécies arbóreas são, predominantemente, as mesmas encontradas nas matas fechadas, porém com diâmetro e altura inferiores. Como as árvores são bem espaçadas, o dossel é aberto e a luminosidade no sub-bosque é elevada. Assemelhamse a uma área de ecótono (transição) entre fragmentos florestais, com intenso processo de sucessão ecológica, sendo possível encontrar grande quantidade de poáceas (gramíneas), ciperáceas e touceiras (Souza, 2014; White et al., 2017).

\section{Distribuição das parcelas}

A coleta do material combustível foi feita em delineamento inteiramente casualizado, onde, com o auxílio de um gabarito de cano PVC (1,5 m x 1,5 m), foram demarcadas 20 parcelas em cada um dos ambientes pré-estabelecidos, totalizando 60 amostras. Essas coletas foram realizadas no período de janeiro a outubro de 2015, abrangendo períodos secos e chuvosos na região. 
Todo o material foi coletado por amostragens destrutivas, onde, toda a biomassa vegetal até $1,8 \mathrm{~m}$ de altura (limite do material combustível superficial) foi recolhida e classificada com base nos modelos de Rothermel (1972) e Brown (1974) (Tabela 1).

Tabela 1. Classificação do material combustível com base nos modelos propostos por Rothermel (1972) e Brown (1974).

Table 1. Classification of the fuel load based on the models proposed by Rothermel (1972) and Brown (1974).

\begin{tabular}{|c|c|c|c|}
\hline Classe & Sub-Classe & Timelag & Diâmetro \\
\hline \multirow{2}{*}{$\begin{array}{l}\text { Material } \\
\text { combustível } \\
\text { vivo }\end{array}$} & $\begin{array}{l}\text { Material } \\
\text { herbáceo } \\
(\text { MHerb) }\end{array}$ & \multirow[t]{2}{*}{ 1-h timelag } & \multirow[t]{2}{*}{$\leq 0,70 \mathrm{~cm}$} \\
\hline & $\begin{array}{c}\text { Material verde } \\
\text { Lenhoso (MVL) }\end{array}$ & & \\
\hline \multirow{3}{*}{$\begin{array}{c}\text { Material } \\
\text { combustível } \\
\text { seco (morto) }\end{array}$} & $\begin{array}{c}\text { Material seco } 1 \\
(\mathrm{MS} 1)\end{array}$ & 1-h timelag & $\leq 0,70 \mathrm{~cm}$ \\
\hline & $\begin{array}{l}\text { Material seco } 2 \\
(\mathrm{MS} 2)\end{array}$ & $\begin{array}{c}10-\mathrm{h} \\
\text { timelag }\end{array}$ & De $0,71<\mathrm{a} \leq 2,50 \mathrm{~cm}$ \\
\hline & $\begin{array}{c}\text { Material seco } 3 \\
(\mathrm{MS} 3)\end{array}$ & $\begin{array}{c}\text { 100-h } \\
\text { timelag }\end{array}$ & De $2,51<\mathrm{a} \leq 7,60 \mathrm{~cm}$ \\
\hline
\end{tabular}

Os combustíveis secos com diâmetro superior a $7,6 \mathrm{~cm}$ e verde-lenhosos com diâmetro superior a $0,7 \mathrm{~cm}$ foram descartados por não contribuírem com a propagação do fogo superficial, de acordo com o modelo de Rothermel (1972).

Após classificação, a massa do material coletado foi determinada com o auxílio de balança digital com precisão de $5 \mathrm{~g}$. Subamostras de cada classe foram retiradas, determinadas as massas, armazenadas em sacos de papel e levadas à estufa de secagem em laboratório, sob temperatura constante de $100{ }^{\circ} \mathrm{C}$, durante $24 \mathrm{~h}$, para determinação da massa seca e do teor de umidade.

\section{Análise estatística}

Inicialmente, foram definidos os valores médios, variância e desvio padrão para a carga e para a umidade do material combustível de todas as classes em cada uma das formações vegetacionais avaliadas nesse estudo.

Os testes estatísticos não paramétricos KruskalWallis e Mann-Whitney, foram utilizados para verificar a existência de diferença significativa entre as médias da carga do material combustível para cada ambiente avaliado. Todos os testes foram realizados ao nível de 5\% de significância com auxílio do programa JMP statistical package (versão 10.0).

Tabela 2. Quantificação do material combustível seco em distintas áreas avaliadas do Refúgio de Vida Silvestre Mata do Junco, Capela, SE.

Table 2. Quantification of the dry fuel load in different vegetation types present in the Wildlife Refuge Mata Junco, Capela, Sergipe, Brazil.

\begin{tabular}{ccccccc}
\hline \multicolumn{7}{c}{ Massa média (t ha $\left.{ }^{-1}\right)$} \\
\hline Áreas & MS $_{1}$ & $\mathbf{M S}_{2}$ & MS $_{3}$ & MHerb & MVL & Total $(\mathbf{n}=\mathbf{2 0})$ \\
\hline Bambuzal & $6,75 \pm 3,16$ & $0,23 \pm 0,48$ & - & $0,04 \pm 0,06$ & $0,58 \pm 0,49$ & $7,60^{\mathrm{A}}$ \\
Mata fechada & $5,54 \pm 1,78$ & $0,40 \pm 0,54$ & $0,19 \pm 0,82$ & $0,33 \pm 0,35$ & $0,56 \pm 0,55$ & $7,02^{\mathrm{A}}$ \\
Transição & $1,35 \pm 0,87$ & $0,13 \pm 0,27$ & - & $0,25 \pm 0,12$ & $0,35 \pm 0,36$ & $2,08^{\mathrm{B}}$ \\
\hline Média & 4,55 & 0,25 & 0,06 & 0,21 & 0,50 & 5,56 \\
\hline
\end{tabular}

*Nota: \pm representa o desvio padrão; médias seguidas de letras diferentes são significativamente diferentes com base no teste Mann-Whitney. MS $=$ material seco; $\mathrm{MHerb}=$ material herbáceo; $\mathrm{MVL}=$ material vivo lenhoso.

\section{Resultados}

Foram coletados $117,23 \mathrm{~kg}$ de material combustível úmido nas 60 parcelas de $2,25 \mathrm{~m}^{2}$. Este material apresentou teor de umidade médio de $35,4 \%$, ou seja, equivalendo a uma massa seca de $75,70 \mathrm{~kg}\left(5,56 \mathrm{t} \mathrm{ha}^{-1}\right)$. As áreas de bambuzal $\left(7,60 \mathrm{t} \mathrm{ha}^{-1}\right)$ e de mata fechada $\left(7,02 \mathrm{tha}^{-1}\right)$ apresentaram os maiores valores de material combustível coletado. Dentre as classes de material combustível pré-estabelecida, a $\mathrm{MS}_{1}$ foi a que mais se destacou, sendo a mais abundante em todos os ambientes analisados (Tabela 2).

Levando-se em consideração que os dados obtidos não apresentaram variância homogênea, foi aplicado o teste não paramétrico Kruskal-Wallis que comprovou a existência de diferença significativa entre a carga do material combustível nos três distintos ambientes avaliados $(\mathrm{H}=38,47 ; \mathrm{p}<0,001)$. Comparando as médias entre pares, o teste Mann-Whitney indicou não existir diferença significativa entre as áreas de mata fechada e de bambuzal que, por sua vez, diferiram significativamente das áreas de transição.

\section{Teor de umidade do material combustível}

As áreas de mata fechada apresentaram os maiores valores médios de umidade do material combustível para todas as classes de timelag pré-estabelecidas, sendo seguida pelas áreas de transição (Figura 2). 


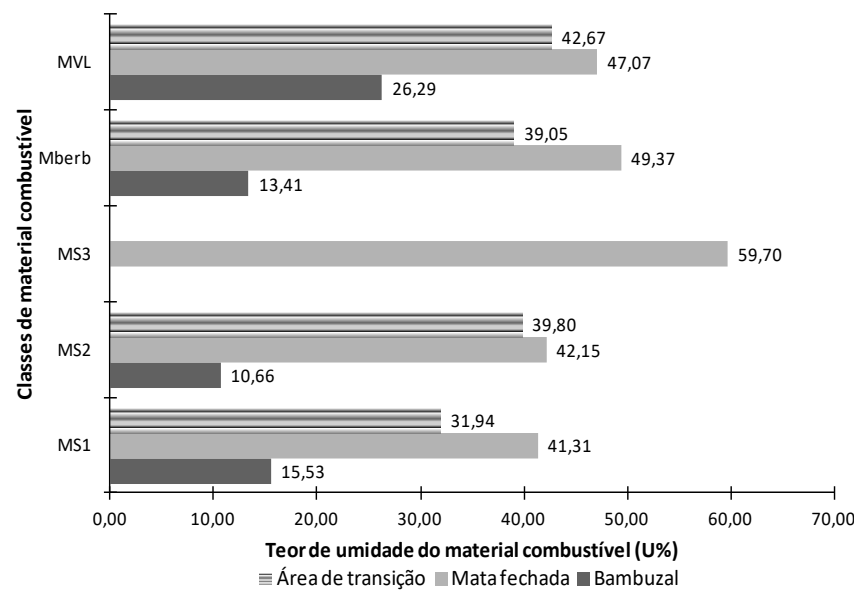

Figura 2. Teor de umidade médio das classes de material combustível coletadas nas três distintas formações vegetacionais do Refúgio de Vida Silvestre Mata do Junco, Capela, SE.

Figure 2. Average moisture content of the fuel load classes collected in three different vegetations types at Mata Junco Wildlife Refuge, Capela, Sergipe, Brazil.

\section{Discussão}

Os principais fatores que exercem influência direta na quantidade de material combustível encontrada em um determinado ecossistema são as espécies, o espaçamento e a idade da vegetação (Soares \& Batista, 2007). A estimativa das respectivas variáveis constitui um dos principais passos para a avaliação do comportamento do fogo, planejamento das atividades de combate, delineamento dos métodos de prevenção e realização de queimas controladas, sendo, normalmente, medidas através de amostragens destrutivas e expressa em termos de massa seca ao forno por unidade de área.

O valor médio da quantidade de material combustível presente nas matas fechadas encontrado neste estudo (7,02 tha $\left.\mathrm{ha}^{-1}\right)$, encontra-se abaixo da maioria dos relatos encontrados na literatura para áreas florestais. White et al. (2014b), por exemplo, encontraram um valor médio de $12,5 \mathrm{t} \mathrm{ha}^{-1}$ para áreas de Floresta Estacional Semidecidual de Terras Baixas localizadas no Parque Nacional Serra de Itabaiana, Sergipe, que distam cerca de $60 \mathrm{~km}$ da Mata do Junco. Souto et al. (2009), em um fragmento de Mata Atlântica no Brejo da Paraíba, encontraram valores médios de 19,47 t ha-1 . No Parque Nacional de Iguaçu, Melo et al. (2006) encontraram média de 11,51 tha ${ }^{-1}$ de material combustível superficial em Floresta Ombrófila Mista e 11,96 tha ${ }^{-1}$ em Floresta Estacional Semidecidual. Na Floresta Tropical Amazônica, Cochrane et al.
(1999) mensuraram um valor médio de $23,3 \mathrm{t} \mathrm{ha}^{-1} \mathrm{de}$ material combustível disponível em uma área de mata conservada e sem prévia ocorrência de incêndios. $\mathrm{O}$ estudo publicado por Camargos et al. (2015), realizado em uma Floresta Estacional Semidecidual em Viçosa, $\mathrm{MG}$, foi o único encontrado em que a quantidade média de material combustível mensurada em área de floresta fechada $\left(5,62 \mathrm{t} \mathrm{ha}^{-1}\right)$ foi inferior ao encontrado neste estudo.

Comparar o valor da carga de material combustível média medida nas de áreas de transição na Mata do Junco com demais trabalhos é complicado, já que são raros os estudos que avaliam esta variável em áreas de regeneração. Além disso, a quantidade de material pode variar consideravelmente, dependendo do estado de regeneração (inicial, secundário ou tardio) e do tipo de vegetação predominante (Soares \& Batista, 2007). Neste estudo em particular, a carga média de 2,08 tha-1 de material combustível disponível, com presença de pouco material lenhoso e predomínio de materiais finos mortos ou vivos da classe de $1 \mathrm{~h}$ de timelag, indicam que a área avaliada se encontra em estágio inicial de regeneração. Cabe mencionar o estudo realizado por White et al. (2014b), que definiram um valor médio de 9,18 t ha-1 para áreas de regeneração secundária no Parque Nacional Serra de Itabaiana. Apesar das similaridades fitofisionômicas em ambas as áreas de estudo, a maior disponibilidade de material combustível disponível nas áreas de regeneração do Parque Nacional Serra de Itabaiana se deve, principalmente, ao estado avançado de regeneração, com presença de materiais lenhosos, inclusive da classe de $100 \mathrm{~h}$ de timelag, contribuindo significativamente com o aporte total da biomassa disponível.

O baixo valor médio da carga do material combustível disponível nas áreas de transição $\left(2,08 \mathrm{t} \mathrm{ha}^{-1}\right)$ sugere elevada dificuldade do fogo se propagar nestes ambientes já que, de acordo com Hély et al. (2003), uma quantidade de material combustível inferior a 2,5 t ha $^{-1}$ é, geralmente, insuficiente para propagar um incêndio florestal.

Apesar da densidade arbórea nas áreas de bambuzal ser inferior à das matas, a quantidade de material combustível média foi levemente superior na primeira $\left(7,6 \mathrm{t} \mathrm{ha}^{-1}\right)$. Essa maior quantidade pode, em parte, ser justificada pelo fato da espécie Phylostachys aurea ser exótica (Santos et al., 2012). De acordo com Ziller (2006), plantas exóticas podem produzir alterações em propriedades ecológicas essenciais, tais como 
ciclagem de nutrientes e produtividade vegetal, além de geralmente possuírem baixas taxas de decomposição. Todos esses fatores contribuem com um maior acúmulo de material combustível sobre o solo em áreas plantadas com espécies exóticas, aumentando assim o risco/perigo de ocorrência de incêndios florestais de grande porte.

Alguns estudos realizados com espécies exóticas florestais comprovam a rapidez com que determinadas espécies acumulam uma grande quantidade de material combustível em um curto intervalo de tempo. Em povoamentos de Pinus taeda L. com 17 anos de idade, no estado de Santa Catarina, Souza et al. (2003a), obtiveram valores médios de $21,10 \mathrm{tha}^{-1}$ de material combustível seco. Em plantio de Tectona grandis Linn. F. no município de Sinop, MT, com 20 anos de idade, Santos et al. (2017) definiram a carga média em 23,2 t ha-1 . Para cultivos de Pinus elliottii Engel com 31 anos de idade, no Paraná, Beutling et al. (2012) determinaram o valor médio de 35,34 t ha-1. Plantações com 6 anos de idade de Eucalyptus grandis W.Hill ex Maiden no litoral norte da Bahia apresentaram um valor médio de $11,31 \mathrm{t} \mathrm{ha}^{-1}$ de material combustível seco, de acordo com White et al. (2014a), e plantações de Eucalyptus dunnii Maiden em Três Barras, SC, com 10 anos de idade, apresentaram um valor médio de 30,82 $\mathrm{t} \mathrm{ha}^{-1}$ de material combustível disponível (Souza et al., 2003b). Todos os trabalhos mencionados apresentaram quantidade superior de material combustível disponível quando comparada com os valores obtidos nas diferentes fitofisionomias analisadas neste estudo.

Embora a quantidade de material combustível seja um dos principais componentes que irá intervir na intensidade do fogo (Rothermel, 1972; Soares \& Batista, 2007; White et al., 2013a, 2014a), a umidade em que o material se encontra constitui o principal fator que define a probabilidade da vegetação entrar em ignição e a facilidade com que o fogo se propagará (Schroeder \& Buck, 1970). O seu valor dependerá das condições ambientais nos últimos dias e horas, sendo que a precipitação pluviométrica, umidade relativa do ar e temperatura do ar são as principais variáveis meteorológicas que exercem influência (Schroeder \& Buck, 1970; Soares \& Batista, 2007; White, 2018).

Quanto maior o teor de umidade, maior será a quantidade de energia necessária para que o material entre em ignição, pois antes do material queimar, é necessário que toda a sua água seja evaporada (White,
2018). Materiais com teores de umidade acima de $30 \%$ costumam não entrar em ignição durante os incêndios florestais (Rothermel, 1972; Soares \& Batista, 2007; Fernandes et al., 2008). Esta é chamada umidade de extinção do material combustível.

No presente trabalho, todas as classes de material combustível das áreas de mata fechada e de transição apresentaram teor de umidade médio acima da umidade de extinção do material combustível, indicando que a probabilidade de ocorrência de incêndios florestais nessas áreas é mínima. A área de bambuzal apresentou o menor teor médio de umidade, sendo que em todas as classes os valores estiveram abaixo da umidade de extinção.

Embora os três ambientes analisados estejam situados em locais próximos e com o mesmo padrão climático, as condições microclimáticas, ou seja, as condições climáticas particulares de uma área pequena e próxima ao solo, podem variar consideravelmente de um ambiente para outro (Rosenberg et al., 1983). White \& Silva (2016), ao analisarem as diferentes condições microclimáticas existentes no interior de um fragmento de Mata Atlântica e em uma área de regeneração primária adjacente, distando $650 \mathrm{~m}$ entre si, comprovaram uma diferença significativa de aproximadamente $2{ }^{\circ} \mathrm{C}$ na temperatura do ar média e de $9 \%$ na umidade relativa do ar média.

Embora as diferenças microclimáticas em cada uma das áreas avaliadas neste estudo não tenham sido quantificadas, acredita-se que, em função da alta densidade da copa nas áreas de mata fechada, a entrada de radiação solar em seu sub-bosque seja reduzida, resultando assim em temperaturas mais amenas, maior umidade relativa do ar e, consequentemente, maior teor de umidade do material combustível. Tal hipótese justifica o maior teor de umidade encontrado em todas as classes de material combustível nas matas fechadas.

\section{Conclusões}

As áreas de mata fechada, de transição e de bambuzal apresentaram distintos valores de carga e de umidade do material combustível, sugerindo assim, diferentes características inerentes ao comportamento do fogo e sua probabilidade de entrar em ignição.

As áreas de bambuzal são os locais que apresentam um maior risco de ocorrência de incêndios florestais, 
uma vez que abrigam maiores quantidades de material seco de fácil ignição. Essa preocupação se intensifica ainda mais devido à proximidade dessas áreas com plantações de cana-de-açúcar que circundam a unidade de conservação.

Ressalta-se a importância de associar o conhecimento adquirido neste trabalho com programas especializados em modelagem do comportamento do fogo, para auxiliar na elaboração de planos operativo de prevenção e combate a incêndios florestais.

\section{Agradecimento}

À FAPITEC/SE e ao CNPq pelo auxílio financeiro concedido para o desenvolvimento deste estudo.

\section{Referências}

Andrews, P. L. et al. BehavePlus fire modeling system: version 2.0 user's guide. Ogden, UT: USDA Forest Service, 2003. (General technical report, RMRS-GTR-106WWW).

Beutling, A. et al. Caracterização e modelagem de material combustível superficial em povoamentos de Pinus elliottii. Floresta, v. 42, n. 3, p. 443-452, 2012. DOI: 10.5380/rf.v42i3.24105.

Brown, J. K. Handbook for inventorying downed woody material. Ogden: USDA Forest Service, 1974. (General technical report INT, 16).

Camargos, V. L. et al. Estudo do comportamento do fogo em um trecho de floresta estacional semidecídua no município de Viçosa, Minas Gerais. Ciência Florestal, v. 25, n. 3, p. 537-545, 2015. DOI: 10.5902/1980509819605.

Cochrane, M. A. et al. Positive feedbacks in the fire dynamic of closed canopy tropical forests. Science, v. 284, n. 5421, p. 1832-1835, 1999.

Dantas, T. V. P. et al. Caracterização florística. In: Sergipe. Secretaria de Estado do Meio Ambiente e dos Recursos Hídricos (Org.). Estudo técnico para a criação do Refúgio de Vida Silvestre da Mata do Junco, Capela, Sergipe. São Cristóvão: Universidade Federal de Sergipe, 2007

Dantas, T. V. P. \& Ribeiro, A. S. Caracterização da vegetação do Parque Nacional Serra de Itabaiana, Sergipe, Brasil. Biotemas, v. 23, n. 4, p. 9-18, 2010. DOI: 10.5007/2175-7925.2010v23n4p9.

Fernandes, P. A. M. et al. Using fuel and weather variables to predict the sustainability of surface fire spread in maritime pine stands. Canadian Journal of Forest Research, v. 38, n. 2, p. 190-201, 2008. DOI: 10.1139/X07-159.

Fernandes, P. A. M. \& Loureiro, C. Fine fuels consumption and $\mathrm{CO}_{2}$ emissions from surface fire experiments in maritime pine stands in northern Portugal. Forest Ecology and Management, v. 291, p. 344-356, 2013. DOI: 10.1016/j.foreco.2012.11.037.
Finney, M. A. FARSITE: fire area simulator: model development and evaluation. Ogden, UT: USDA Forest Service, 2004. (Research Paper RMRS-RP-4 Revised).

Hély, C. et al. Regional fuel load for two climatically contrasting years in southern Africa. Journal of Geophysical Research, v. 108, n. D13, p. 1-17, 2003. DOI: 10.1029/2002JD002341.

IBGE. Manual técnico da vegetação brasileira. 2. ed. Rio de Janeiro, 2012.

Liu, Y. et al. Trends in global wildfire potential in a changing climate. Forest Ecology and management, v. 259, n. 4, p. 685-697, 2010. DOI: $10.1016 /$ j.foreco.2009.09.002.

Malta, J. A. O. et al. A contraditória relação sociedade-natureza em espaços territoriais protegidos - Mata do Junco, Capela/SE. Geografia em Questão, v. 4, n. 1, p. 126-152, 2011.

Mataix-Solera, J. et al. Fire effects on soil aggregation: a review. Earth-Science Reviews, v. 109, n. 1-2, p. 44-60, 2011. DOI: 10.1016/j.earscirev.2011.08.002.

Melo, L. A. M. N. et al. Modelagem de combustíveis florestais no Parque Nacional do Iguaçu, PR, Brasil. Floresta, v. 36, n. 3, 2006. DOI: $10.5380 /$ rf.v36i3.7520.

Moreno, M. R. et al. Estrutura e composição florística do estrato arbóreo em duas zonas altitudinais na Mata Atlântica de encosta da região do Imbé, RJ. Acta Botânica Brasílica, v. 17, n. 3, p. 371-386, 2003. DOI: $10.1590 / \mathrm{S} 0102-33062003000300005$.

Moretti, M. \& Legg, C. Combining plant and animal traits to assess community functional responses to disturbance. Ecography, v. 32, n. 2, p. 299-309, 2009. DOI: 10.1111/j.1600-0587.2008.05524.x.

Ribeiro, G. A. A queima controlada no manejo da terra. In: Soares, R. V. et al. (Ed.). Incêndios florestais no Brasil: o estado da arte. Curitiba: Universidade Federal do Paraná, 2009.

Rosenberg, N. J. et al. Microclimate: the biological environment. New York: John Wiley \& Sons, 1983.

Rothermel, R. C. A mathematical model for predicting fire spread in wildland fuels. Ogden, UT: USDA Forest Service, 1972. (Research paper INT-115).

Santos, J. C. H. et al. Quantificação de material combustível na serapilheira de plantio de Tectona Grandis Linn.F. Scientific Electronic Archives, v. 10, n. 2, p. 68-72, 2017.

Santos, M. J. S. et al. Biomonitoramento através de indicadores ambientais abióticos - Mata do Junco (Capela-SE). Scientia Plena, v. 3, n. 5, p. 142-151, 2007

Santos, S. C. et al. Regeneração de espécies arbóreas sob a influência de Merostachys multiramea Hack. (Poaceae) em uma floresta subtropical. Acta Botânica Brasílica, v. 26, n. 1, p. 218-229, 2012. DOI: 10.1590/S0102-33062012000100021.

Schroeder, M. J. \& Buck, C. C. Fire weather: a guide for application of meteorological information to forest fire control operations. Ogden, UT: USDA Forest Service, 1970. (Agriculture Handbook 360).

Soares, R. V. \& Batista, A. C. Incêndios florestais: controle, efeitos e uso do fogo. Curitiba: Universidade Federal do Paraná, 2007. 
Souto, P. C. et al. Quantificação do material combustível em plantios florestais e em remanescente de mata atlântica no brejo da Paraíba, Brasil. Engenharia Ambiental: Pesquisa e Tecnologia, v. 6, n. 3, p. 473-481, 2009.

Souza, H. T. R. Conservação ambiental de remanescente florestal: Mata do Junco em questão. São Cristovão: EDUFS, 2014.

Souza, L. J. B. et al. Modelagem de material combustível em plantações de Pinnus taeda no norte de Santa Catarina. Floresta, v. 33, n. 2, p. 157-168, 2003a. DOI: 10.5380/rf.v33i2.2355.

Souza L. J. B. et al. Modelagem do material combustível superficial em povoamentos de Eucalyptus dunnii, em Três Barras, SC. Cerne, v. 9 , n. 2, p. 231-245, 2003 b.

Torres, F. T. P. et al. Correlações entre elementos meteorológicos e as ocorrências de incêndios florestais na área urbana de Juiz de Fora, MG. Revista Ávore, v. 35, n. 1, p. 143-150, 2011. DOI: 10.1590/ S0100-67622011000100017.

Ziller, S. R. Espécies exóticas da flora invasoras em Unidades de Conservação. In: Campos et al. (Eds) Unidades de Conservação: ações para valorização da biodiversidade. Curitiba: Instituto Ambiental do Paraná, 2006. p. 34-52.

White, B. L. A. Modelos matemáticos de previsão do teor de umidade dos materiais combustíveis florestais finos e mortos. Ciência Florestal, v. 28, n. 1, p. 432-445, 2018. DOI: 10.5902/1980509831622.

White, B. L. A. et al. Avaliação e simulação do comportamento do fogo em diferentes fitofisionomias de uma área de Mata Atlântica do nordeste brasileiro. Floresta, v. 47, n. 3, p. 247-256, 2017. DOI: 10.5380/rf.v47i3.50844.
White, B. L. A. et al. Building fuel models and simulating their surface fire behavior in the "Serra de Itabaiana" National Park, Sergipe, Brazil. Floresta, v. 43, n. 1, p. 27-38, 2013a. DOI: 10.5380/ rf.v43i1.28034.

White, B. L. A. et al. Caracterização do material combustível e simulação do comportamento do fogo em eucaliptais no litoral norte da Bahia, Brasil. Floresta, v. 44, n. 1, p. 33-42, 2014a. DOI: 10.5380/rf.v44i1.32977.

White, B. L. A. et al. Caracterização do material combustível superficial do Parque Nacional Serra de Itabaiana - Sergipe, Brasil. Ciência Florestal, v. 24, n. 3, p. 699-706, 2014b. DOI: 10.5902/1980509815727.

White, B. L. A. et al. Development of a fire danger index for Eucalypt plantations in the northern coast of Bahia, Brazil. Floresta, v. 43, n. 4, p. 601-610, 2013b. DOI: 10.5380/rf.v43i4.30973.

White, B. L. A. et al. O uso do BehavePlus como ferramenta para modelagem do comportamento e feito do fogo. Pesquisa Florestal Brasileira, v. 33, n. 73, p. 73-84, 2013c. DOI: 10.4336/2013. pfb.33.73.409.

White, B. L. A. \& Silva, M. F. A. Avaliação das condições microclimáticas no interior de fragmentos de Mata Atlântica em distintos graus de conservação no município de São Cristóvão, Sergipe. In: Seabra, G. (Org.). Educação ambiental \& biogeografia. Ituiutaba: Barlavento, 2016. p. 571-578. 